\section{JANET CLARKE: 'WE WILL INCREASINGLY SEE DENTISTS BEING SALARIED'}

Janet Clarke is the Associate Director of the Birmingham Community Healthcare Trust Combined Community Dental Service. Janet is also an honorary clinical lecturer at Birmingham Dental School and a past-president of the British Dental Association. She worked alongside Jimmy Steele in his Independent Review of NHS Dentistry in 2008 and two years later was awarded an MBE for services to dentistry.

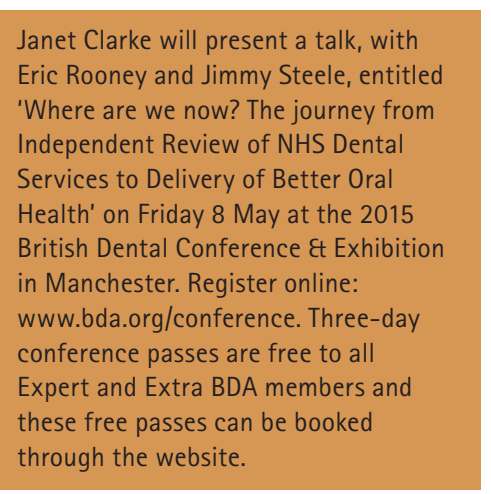

Janet Clarke will present a talk, with Eric Rooney and Jimmy Steele, entitled 'Where are we now? The journey from Independent Review of NHS Dental Services to Delivery of Better Oral Health' on Friday 8 May at the 2015 British Dental Conference \&t Exhibition in Manchester. Register online: conference passes are free to all Expert and Extra BDA members an these free passes can be booked through the website.

\section{What is your typical week like?}

At the moment I'm managing the community dental service and the dental hospital in Birmingham we're integrating the two together to one service - so my week can involve being with community dentists or it can involve being at the dental hospital.

Sometimes, I might have a week like this one during which I've been to London three times. At the moment I'm chairing the commissioning guide work for special care dentistry for NHS England; so this week I came and chaired that group, which meant meeting lots of people across the country and trying to get them to agree. Today, I am here at the BDA Careers Day at Senate House. I also chair our local professional network for dentistry in Birmingham and the Black Country. I haven't had any evening meetings this week but they are not unusual! I usually have a very meeting-based week with lots of variety, working with many different people.

You clearly attend a lot of meetings - do you have any tips for running the ideal meeting?

I have lots of tips!

1. A meeting needs to be chaired properly. The chair needs to know what they're doing and they need to know what they want to get out it

2. It needs to have an agenda. Peter Lowndes, an old BDA colleague, once said 'if a

nd

'If you ask my family, they would say I would have made a fantastic MP...'

\section{(1)}

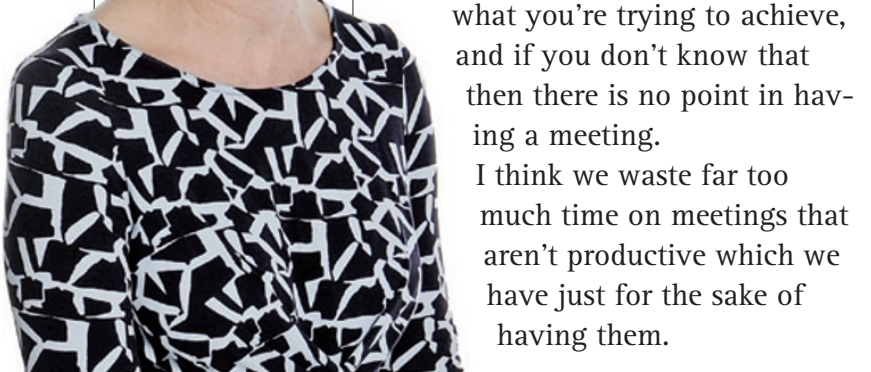

Did you ever consider doing anything other than dentistry?

I considered law. I chose dentistry because I was good at science and my parents were very much of the opinion that I would have more opportunities in that field. I'm quite a practical person so dentistry was ideal really. I like meeting people, I like doing things, and dentistry is good because you can have some fairly immediate gratification - a patient comes in with a problem, you sort the problem out, they go home happy and you've got that immediate satisfaction. If you ask my family what I should have done, they would say I would have made a fantastic MP! I do think now that's what I should have done.

\section{Why did you choose to} specialise in community dentistry?

I worked in general practice for a while and that meant always practising dentistry in the same place. Community dentistry, allowed more variety because you were based in different clinics. When I first joined the community dental service it still carried out school screening, so we were out at school quite a lot or going on domiciliary visits with different teams and different people. I also preferred being part of a bigger team. Sometimes in a general practice there are a couple of dentists, a couple of nurses and that's it - the same people every day! In a bigger team there is more variety, so that was why I chose it. It suited me.

\section{What do you think is the future for dentistry in the UK?}

I think that we will have fewer but bigger dental practices, or dental practices will federate and come together. Increasingly, patients are going to want to have all their needs met in one place or by one practice, and a small/single-handed practice is going to find it much more difficult to get the specialists to come in or to find the full range of specialist skills. If practices come together, in the same way as medicine, then you can imagine 
that you could get your consultants to come out and do a session so patients could have their care closer to home. This is where the future is going isn't it?

I think we'll increasingly see dentists being salaried. If you look at the makeup of the profession, having salaries could be quite attractive and often the way people see UDAs means it's almost like a salary anyway. By salaried I mean a 'partnership model' maybe, as there is in law; so with senior partners who own the practice and then they have their employees, rather than associates. I certainly think we'll see more management, ie practices will become more managed with an employee model.

We'll see more skill mix in dentistry - so those bigger practices will probably be employing more therapists, hygienists and dental nurses with extended skills. I see dentistry working a lot more closely with medicine, particularly considering the common risk factors such as sugar, smoking, obesity and diabetes. So I think we'll see people working more closely together and consultants working more in community.

I think the inequalities agenda is really important. That hasn't been fully addressed in dentistry and we could make a massive improvement in oral health by concentrating on the people who aren't using dentists at the moment or who aren't getting the treatment that they need.

\section{How do you get to the people who need the most help?}

The bigger practices, or federations, could have more outreach into the community - for example, a federated practice could have links with care homes that they looked after and the employed dentists or DCPs could go out and do that. It might also be possible to partner with schools in a much more formal way than is happening now. People in the commissioning services would need to understand that the dental practice, as part of its contract, was looking after ' $x$ ' number of care homes, and ' $x$ ' number of schools etc. So that you've actually got the dental team out in the community being far more visible and getting the patients to come.
If you were put in charge of the GDC - what are the first three things you would want to achieve with regards to regulation?

Considering external factors first because I think that is really important. The profession is currently demoralised and feels threatened by the GDC - the relationship is not good. So I think the first thing that I would do is look to build bridges with the profession. Part of that is around acknowledging that there is a problem and we need to move forward. So first of all, I would undertake a big engagement exercise with the profession - the $\mathrm{BDA}$, the royal colleges, local dental committees, anywhere and everywhere. The message would need to be: 'The GDC is changing, we want to go forward in a positive way'. I think that's fundamental.

At the same time there is the internal side that needs to be examined and I would want to look at exactly what was happening with committee structures and meetings in order to reduce the waste. I still feel there is a lot of waste that could be eliminated, eg around bringing people to London and putting them up overnight. We need more use of telecoms and Skype.

And the third thing would be regarding the public because my view is that complaints and issues need to be dealt with locally. I think patients need to be encouraged to take their complaints to the practice in the first instance. And if they can't take them to the practice, well they have to go to NHS England don't they? But we need to try to get things resolved locally before they get escalated to the GDC. Currently, it's completely the wrong way round. And lastly, I think the GDC should work more closely with the CQC to avoid duplication and so that they can be quite clear on who is doing what.

\section{We are increasingly hearing that the NHS on shaky ground - how would you recommend that resource and care be balanced in the future?}

I think it comes back to the inequalities really. We need to concentrate our resources on reducing that gap. I don't feel we overtly do that at the moment, so we need to think through
'The

profession is currently demoralised and feels threatened by the GDC...' how we can close the gap. Dentistry needs to be organised differently.

\section{Why don't we already concentrate our resources on reducing the inequalities gap?}

I think it's because of the way dentists are trained and how the contract is set up. Dentists are trained and the contract set up to deliver activity. You can deliver activity by waiting for patients to come and see you, and you have to do that because if you're not delivering the activity, then you're going to lose money aren't you?

So I think that we need commissioners to be far braver and commission blocks of service. For example, they could commission some GDPs and say 'Okay, we'll give you this amount of money to look after this care home (or whatever you need to target) and don't worry about the UDAs attached to that, but actually you're going to get this money to do that particular piece of work.' You could monitor it through looking at the outcomes being achieved and delivering what you set out to. So, I think the way the commissioning is done needs to change and that means the commissioners being a lot braver than they are at the moment in order to move away from a UDA-focussed contract to be more innovative and to commission different things.

That's one of the things I would do.

The other thing we need to do is be a lot cleverer around prevention. A lot of work is being done by other groups, not by dentists and not paid out of the dental budget. We need to tie ourselves into that work. For example, when work is being done around diabetes, we need to ensure that diabetes specialists and nurses are being trained to understand the link between diabetes and oral health, and are able to signpost patients properly to get the oral health advice that they need. Because then that piece of work is being done by the diabetes specialists and nurses and using diabetes money, not dental money. I think that's the clever way to do it.

How do you incentivise dentists to go to the more tricky patients in the community?

That's a difficult question. You can only do it by engaging with the profession locally. I don't think you can 
do it by compulsion and realistically we won't have a pot of money to specifically do this. You can engage with the profession through the local professional networks (LPNs); with commissioners working with the local profession through the LPNs to identify the areas where we could improve things and then actually involve the profession locally to figure out how it can be done. You will find there are dentists who will do this because there are really good dentists who care about things. And if a commissioner was to say 'Okay, I'll give you the same amount of money but this time I want you to do a reduced number of UDAs and instead do this piece of interesting innovative work', there are dentists who will do it. It can be more fulfilling.

You worked on the Independent Review of Dentistry with Jimmy Steele - what is the most challenging aspect of preparing this report?

The first one was the timescale. We
'I think that we need commissioners to be far braver...' had to do it in such a short time and we set ourselves a really challenging agenda because we wanted to engage the profession and the public and we wanted to do a thorough job. We were hard on ourselves I think. We got around it by dividing ourselves up so that each of us took an area and looked at it in more detail; I was closely involved with the patient elements.

The other challenge was that the majority of us on the team liked talking a lot. We all had loads of ideas and wanted to talk about it so we had to be disciplined with ourselves. At one point you could only talk if you were holding "the table mat'. And then we found there were lots of other table mats! We had a lot of fun. We are doing a talk on the review revisited at the British Dental Conference and Exhibition 2015 - I'm looking forward to that.

\section{What do you enjoy doing in your spare time?}

I have lots of friends I like to socialise with! I have very good networks both within the profession and outside it. I'm in a couple of book groups - we just finished Donna Tartt's The goldfinch. I also have two children who I like to spend time with.

\section{Who do you most admire?}

That's a really difficult question. I'll sound awfully frivolous but I would say somebody whose style I particularly admire is Anna Wintour (from Vogue). And, for being organised and getting things done, I would say Angela Merkel. I ought to have a nice cuddly person because neither of those are but no! That will have to do!

\section{If you could live and work in any other country in the world} which would you choose?

I would love to live in California (San Francisco, not LA) - just because I think it's a fabulous place. Would I like to work there? I don't know. The place I'd like to work is Scandinavia, that would suit me better as a person.

INTERVIEW BY RUTH DOHERTY 